\title{
Off-Pump Technique May Prevent Worsening of Renal Function in CAD with CKD Undergoing CABG
}

\author{
Shaheen Afsal ${ }^{1} \quad$ K. Sujani ${ }^{1} \quad$ Shashank Viswanathan ${ }^{2} \quad$ Akshay Bhati $^{2} \quad$ Harish BR ${ }^{3} \quad$ Muralidhar Kanchi ${ }^{4}$ \\ ${ }^{1}$ Department of Anaesthesia, Narayana Institute of Cardiac \\ Sciences, Bengaluru, Karnataka, India \\ ${ }^{2}$ Mazumdar Shaw Center for Translational Research, Bengaluru, \\ Karnataka, India \\ ${ }^{3}$ Department of Anaesthesia, Mazumdar Shaw Medical Centre, \\ Bengaluru, Karnataka, India \\ ${ }^{4}$ Anaesthesia and Intensive Care, Narayana Institute of Cardiac \\ Sciences, Bengaluru, Karnataka, India \\ Address for correspondence Muralidhar K, MD, FIACTA, FICA, MBA, \\ FASE, Anaesthesia and Intensive Care,Narayana Institute of Cardiac \\ Sciences, Narayana Health City, University of Minnesota, United States: \\ Indian College of Anaesthesiologists, Narayana Hrudayalaya Institute \\ of Allied Health Sciences, \#258/A, Bommasandra Industrial Area, \\ Anekal Taluk, Bengaluru-560 099, Karnataka, India \\ (e-mail: muralidhar.kanchi.dr@narayanahealth.org, \\ kanchirulestheworld@gmail.com).
}

J Card Crit Care:2021;5:7-11

\begin{abstract}
Keywords

- coronary artery bypass grafting

- creatinine

- glomerular filtration rate

- renal dysfunction

Cardiovascular disease (CVD) is a major cause for a significant proportion of all deaths and disability worldwide. Postoperative renal dysfunction following cardiac surgery is not an uncommon complication of cardiac surgery, which has serious implications with regard to morbidity, mortality, financial expenditure, and resource utilization. This study was performed to compare outcomes of patients with preoperative renal dysfunction with those having normal renal function undergoing off-pump coronary artery bypass grafting (OPCABG). Patients were divided into two categories, depending on their preoperative serum creatinine and glomerular filtration rate (GFR). The preoperative renal dysfunction was defined as serum creatinine $>1.3 \mathrm{mg} / \mathrm{dL}$ and/or estimated GFR (eGFR) of $<60 \mathrm{~mL} / \mathrm{min} / 1.73 \mathrm{~m}^{2}$. The category A patients had normal renal function defined as serum creatinine $\leq 1.3 \mathrm{mg} / \mathrm{dL}$ and/or eGFR of $\geq 60 \mathrm{~mL} / \mathrm{min} / 1.73 \mathrm{~m}^{2}$ while the category $B$ patients had preoperative renal dysfunction that did not necessitate renal dialysis. Blood samples were collected from both category patients for serum creatinine prior to surgery, following surgery, on postoperative days $1,2,3,4,5$, and on the day of discharge. The occurrence of acute kidney injury (AKI) was defined as an increase in the serum creatinine levels of $\geq 0.3 \mathrm{mg} / \mathrm{dL}$ within 48 hours or an increase of $\geq 1.5$ above baseline known or presumed to have occurred within the previous 7 days based on Kidney Disease Improving Global Outcomes criteria. This study demonstrated that there was worsening of renal function in $7.4 \%$ of patients with normal renal function and $10.74 \%$ of patients with renal dysfunction that was not statistically different. Based on the results, we conclude that preoperative renal dysfunction may be a contributing predictor of AKI following OPCABG, and we recommend that the patients with more severe renal dysfunction with eGFR of $45-60 \mathrm{~mL} / \mathrm{min}$ should be studied to demonstrate this hypothesis.
\end{abstract}

DOI https://doi.org/

10.1055/s-0041-1723857

ISSN 2457-0206. (c) 2021. Official Publication of The Simulation Society (TSS), accredited by International Society of Cardiovascular Ultrasound (ISCU).

This is an open access article published by Thieme under the terms of the Creative Commons Attribution-NonDerivative-NonCommercial-License, permitting copying and reproduction so long as the original work is given appropriate credit. Contents may not be used for commercial purposes, or adapted, remixed, transformed or built upon. (https://creativecommons.org/licenses/by-nc-nd/4.0/)

Thieme Medical and Scientific Publishers Pvt. Ltd., A-12, 2nd Floor, Sector 2, Noida-201301 UP, India 


\section{Introduction}

Cardiovascular disease (CVD) is a leading cause of all deaths and disability worldwide. As per the report of Global Burden of Disease in 2017, CVD caused an estimated 17.8 million deaths worldwide, corresponding to 330 million years of life lost and another 35.6 million years lived with disability. ${ }^{1,2}$ It is predicted that by the year 2020, there will be an increase by almost $75 \%$ in global CVD prevalence, and almost all of this increase will occur in developing countries. ${ }^{3}$ Coronary artery bypass grafting (CABG) has an important role in the management of ischemic heart diseases. Cardiopulmonary bypass ( $\mathrm{CPB}$ ) with cardiac arrest (on-pump) provides a surgical field free of motion and blood, allowing safe construction of anastomosis. Yet, the use of CPB is associated with complications peculiar to extracorporeal circulation that may be a major determinant of perioperative morbidity, hospital stay, and costs. As a result, bypass surgery on the beating heart without use of extracorporeal circulation (off-pump) has been introduced successfully in clinical practice. Off-pump coronary artery bypass grafting (OPCABG) avoids serious complications associated with CPB such as stroke, renal dysfunction, and systemic inflammatory response syndrome. OPCABG avoids CPB-induced adverse effects on renal function and is proposed to be the technique of choice for CABG in patients with renal dysfunction. This study was conducted to determine the outcomes of patients with pre-existing renal dysfunction as compared with normal renal function undergoing OPCABG.

\section{Methods}

This study was conducted at a tertiary care heart hospital in a retrospective cohort study design. The ethical clearance was obtained prior to the study and waiver of consent was obtained as anonymized data were collected from medical records. Patients were divided into two categories, depending on the preoperative serum creatinine and glomerular filtration rate (GFR). Sample-size calculation was based on the incidence of acute kidney injury (AKI) reported in a previous article. ${ }^{4}$ All patients undergoing elective OPCABG were included but patients with stage 5 chronic kidney disease (CKD) undergoing dialysis and those undergoing emergency surgery were excluded from the study. The patients who had coronary angiography within 48 hours of planned surgery were excluded from the study to avoid confounding issues due to contrast-induced nephropathy. The category A patients had normal renal function defined as serum creatinine $\leq 1.3 \mathrm{mg} / \mathrm{dL}$ and/or estimated GFR (eGFR) of $\geq 60 \mathrm{~mL} / \mathrm{min} / 1.73 \mathrm{~m}^{2}$. The category B patients had preoperative renal dysfunction, which was defined as serum creatinine $>1.3 \mathrm{mg} / \mathrm{dL}$ and/or eGFR of $<60 \mathrm{~mL} / \mathrm{min} / 1.73 \mathrm{~m}^{2}$. Serum creatinine values on postoperative days $1,2,3,4,5$ and on the day of discharge were recorded from both the categories and the results analyzed for AKI based on the Kidney Disease Improving Global Outcomes (KDIGO) criteria as follows: occurrence of AKI was defined as (i) an increase in the serum creatinine levels of $>0.3 \mathrm{mg} / \mathrm{dL}$ within 48 hours, (ii) an increase of $>1.5$ times the baseline known or presumed to have occurred within the previous 7 days, and (iii) urine output $<0.5 \mathrm{~mL} / \mathrm{kg} / \mathrm{h}$ for 6 hours.

\section{Anesthesia and Surgical Technique}

After a thorough preoperative evaluation and preanesthetic preparation, all antianginal and antihypertensive medications were continued till the morning of surgery with exception of angiotensin converting enzyme inhibitors and angiotensin receptor blockers. Control of comorbid states such as diabetes mellitus was ensured. Sedative premedication consisted of oral alprazolam the night before. Monitoring of electrocardiogram (ECG) with five leads with simultaneous display of leads II and V5 was done and automated ST segment analysis, pulse oximetry, and direct arterial blood pressure measurement were established. After preoxygenation for 3 to 5 minutes, anesthesia was induced with intravenous fentanyl 3 to $5 \mu \mathrm{g} / \mathrm{kg}$, midazolam 0.05 to $0.1 \mathrm{mg} / \mathrm{kg}$, and propofol 0.5 to $1 \mathrm{mg} / \mathrm{kg}$. Muscle paralysis was achieved with pancuronium or vecuronium at the discretion of the anesthesiologist and endotracheal intubation was performed. Anesthesia was maintained with $02+a i r+e n d$ tidal isoflurane of $1 \%$. Fentanyl was used in a total dose of 10 to $15 \mu \mathrm{g} / \mathrm{kg}$ for the entire procedure. The perioperative management was tailored to achieve early extubation and fast-tracking. Heparin in a dose of 300 units/kg was administered prior to the grafting and repeated doses of 100 units/kg every hour till grafting was completed to maintain activated coagulation time over 300 seconds. Reversal of heparinization at the end of grafting was achieved with protamine 1 to $2 \mathrm{mg} / \mathrm{kg}$. Hemodynamic monitoring included ECG, arterial pressure using invasive arterial catheter, and central venous pressure. Pulmonary artery catheter was used in patients with poor left ventricular function, with ejection fraction $<40 \%$, and transesophageal echocardiography was used to assess the cardiac function with special reference to mitral valve function to exclude patients with moderate and severe mitral regurgitation, if any. Urine output was recorded hourly. OPCABG was done after midline sternotomy using myocardial stabilizer (Octopus) for the distal coronary anastomosis. Proximal anastomosis on aorta was performed with a systolic arterial pressure (SAP) of 80 to $90 \mathrm{~mm} \mathrm{Hg}$ and the distal anastomosis performed with SAP of 110 to $120 \mathrm{~mm} \mathrm{Hg}$ unless indicated otherwise. A mean arterial pressure of $70 \mathrm{~mm} \mathrm{Hg}$ was maintained throughout the procedure at times other than indicated above. Patients were electively ventilated for 2 to 4 hours till fully conscious, warm, not bleeding, and then extubated after a short trial of spontaneous respiration.

\section{Statistical Method}

Data were analyzed using SPSS software version 21.0. Continuous variables were expressed as mean \pm standard deviation (SD). Categorical variables were expressed using frequency and percentage. Comparison of continuous variables with presence of AKI was done using independent sample $t$-test or Mann-Whitney $U$ test. For categorical variables, analysis was done using chi-square test or Fisher exact test. A $p$-value $<0.05$ was considered as statistically significant. 


\section{Results}

There was a total of 242 patients in the two groups, 121 in each. There was a male preponderance in both groups. Also, $51 \%$ of patients in category A (those with normal renal function) and $60 \%$ in category $\mathrm{B}$ (those with renal dysfunction) were diabetics. - Table 1 shows that the incidence of AKI was higher in category $\mathrm{B} ; 7.4 \%$ patients in category $\mathrm{A}$ and $10.74 \%$ of patients in category B developed AKI as defined by KDIGO criteria, but this difference was not statistically significant ( $p$ $=0.37$ ). There was significant difference in age among the two groups. The mean of age in category A was $55 \pm 9.6(\mathrm{SD})$ years with a range of 30 to 73 years whereas in category $B$, the mean age was $60.71 \pm 8.1$ (SD) years with a range of 44 to 82 years. There was no statistically significant difference between the two groups when gender, presence of diabetes, hypertension, cerebrovascular disease, smoking, intra-aortic balloon pump (IABP) requirement, incidence of re-exploration, and postoperative stroke were considered. The Euroscore risk was higher for patients with renal dysfunction when compared with patients with normal renal function, which was statistically significant. There was no statistically significant difference between the two groups with respect to left ventricular ejection fraction, number of grafts, requirement for renal replacement therapy (RRT), length of intensive care unit (ICU)/hospital stay, and mortality.

- Table 2 shows statistically significant increase in postoperative serum creatinine levels in category B patients. Also, serum creatinine values showed worsening till postoperative day 3 and then showed improvement indicating recovery of renal function. Statistically significant differences compared with preoperative values were noted from day 1 to day 3 in both the groups $(p<0.001)$.

Table 1 Demographic and clinical data of patients undergoing off-Pump CABG in 2 groups

\begin{tabular}{|c|c|c|c|c|}
\hline & & $\begin{array}{l}\text { Category A (normal renal } \\
\text { function) }\end{array}$ & Category B (renal dysfunction) & p-Value \\
\hline \multicolumn{2}{|l|}{ Age (mean \pm SD) } & $30-73$ years $(55 \pm 9.6)$ & $44-82$ years $(60.71 \pm 8.1)$ & $<0.001$ \\
\hline \multicolumn{2}{|l|}{ Gender (F/M) } & $11 / 110$ & $8 / 113$ & 0.473 \\
\hline \multicolumn{2}{|l|}{ Diabetes $(\mathrm{Y} / \mathrm{N})$} & $62 / 59$ & $73 / 48$ & 0.155 \\
\hline \multicolumn{2}{|l|}{ Hypertension $(\mathrm{Y} / \mathrm{N})$} & $73 / 48$ & $89 / 32$ & 0.029 \\
\hline \multicolumn{2}{|c|}{ Preoperative CVD (Y/N) } & $0 / 121$ & $1 / 120$ & 0.316 \\
\hline \multicolumn{2}{|c|}{ Smoking status $(\mathrm{Y} / \mathrm{N})$} & $41 / 80$ & $44 / 77$ & 0.686 \\
\hline \multicolumn{2}{|c|}{ Preoperative serum creatinine (mg \%) } & $0.96 \pm 0.14$ & $1.46 \pm 0.29$ & $<0.001$ \\
\hline \multicolumn{2}{|c|}{$\begin{array}{l}\text { Preoperative eGFR }(\mathrm{mL} / \mathrm{min}) \text { : } \\
\text { mean } \pm \text { SD }\end{array}$} & $81.13 \pm 13.95$ & $51.07 \pm 9.016$ & $<0.001$ \\
\hline \multirow{4}{*}{$\begin{array}{l}\text { Preoperative eGFR } \\
\text { (mL/min): } \\
\text { categorized }\end{array}$} & $>60$ & 120 & 4 & \\
\hline & $60-45$ & 1 & 93 & \\
\hline & $45-30$ & 0 & 23 & \\
\hline & $<30$ & 0 & 1 & \\
\hline \multicolumn{2}{|l|}{ Euroscore risk ( \pm SD) } & $1.83( \pm 1.7)$ & $2.98( \pm 1.9)$ & $<0.001$ \\
\hline \multicolumn{2}{|l|}{ LVEF \% ( \pm SD) } & $47.40( \pm 7)$ & $47.40( \pm 7)$ & 1 \\
\hline \multicolumn{2}{|c|}{ Number of grafts $( \pm S D)$} & $1.92( \pm 0.7)$ & $1.92( \pm 0.7)$ & 1 \\
\hline \multicolumn{2}{|l|}{ Incidence of AKI } & $9(7.5 \%)$ & $13(10.7 \%)$ & 0.37 \\
\hline \multicolumn{2}{|c|}{ IABP requirement $(\mathrm{Y} / \mathrm{N})$} & $2 / 119$ & $0 / 121$ & 0.156 \\
\hline \multicolumn{2}{|l|}{ Re-exploration $(\mathrm{Y} / \mathrm{N})$} & $4 / 117$ & $0 / 121$ & 0.044 \\
\hline \multicolumn{2}{|c|}{ Postoperative stroke $(\mathrm{Y} / \mathrm{N})$} & $2 / 119$ & $0 / 121$ & 0.156 \\
\hline \multicolumn{2}{|l|}{ ICU stay $( \pm S D)$} & 2.11 days $( \pm 0.4)$ & 2.11 days $( \pm 0.4)$ & 1 \\
\hline
\end{tabular}

Abbreviations: AKI, acute kidney injury; CVD, cardiovascular disease; eGFR, estimated glomerular filtration rate; $F$, female; IABP, intra-aortic balloon pump; ICU, intensive care unit; LVEF, left ventricular ejection fraction; M, male; N, no; SD, standard deviation; Y, yes.

Table 2 Postoperative serum creatinine values in 2 groups of patients from day 1 to 5

\begin{tabular}{|l|l|l|l|}
\hline $\begin{array}{l}\text { Serum creatinine } \\
(\mathbf{m g} \%)\end{array}$ & $\begin{array}{l}\text { Category A (normal renal } \\
\text { function) }\end{array}$ & $\begin{array}{l}\text { Category B (renal } \\
\text { dysfunction) }\end{array}$ & $p$-Value \\
\hline POD-1 & $0.96 \pm 0.218$ & $1.64 \pm 0.311$ & $<0.001$ \\
\hline POD-2 & $0.96 \pm 0.218$ & $1.62 \pm 0.371$ & $<0.001$ \\
\hline POD-3 & $0.99 \pm 0.393$ & $1.74 \pm 0.440$ & $<0.001$ \\
\hline POD-4 & $0.96 \pm 0.382$ & $1.66 \pm 0.385$ & $<0.001$ \\
\hline POD-5 & $0.96 \pm 0.29$ & $1.66 \pm 0.438$ & $<0.001$ \\
\hline
\end{tabular}

Abbreviation: POD, postoperative day. 


\section{Discussion}

Postoperative renal dysfunction is one of the most significant serious complications following cardiac surgery. About $2.3 \%$ of isolated CABG cases are vulnerable to AKI, and the incidence is higher (14-15\%) in patients with preoperative CKD. ${ }^{5}$ However, the incidence of AKI defined by consensus definitions is much higher and $20 \%$ to $30 \%$. 6,7

This study was conducted to determine outcomes of patients with renal dysfunction undergoing OPCABG and compare them with patients with normal renal function undergoing OPCABG. This study was modeled after similar studies done by Kim et al, which showed three times higher risk of AKI in the CKD group than in the normal group, and the overall incidence of AKI was reported in 34 patients (13.9\%). ${ }^{8}$ In our study, the risk of developing AKI in patients with pre-existing renal dysfunction was lower as compared with the study done by Kim et al due to the fact that the patient cohort in our study was having milder renal dysfunction with eGFR value of $51 \mathrm{~mL} / \mathrm{min} / 1.73 \mathrm{~m}^{2}$.

Our study is a retrospective cohort study, wherein patients were divided into two categories. The category A patients were those with normal renal function, which was defined as serum creatinine $\leq 1.3 \mathrm{mg} / \mathrm{dL}$ and/or eGFR of $\geq 60 \mathrm{~mL}$ / $\mathrm{min} / 1.73 \mathrm{~m}^{2}$. The category B patients were those with renal dysfunction, which was defined as serum creatinine $\geq 1.3 \mathrm{mg} /$ $\mathrm{dL}$ and/or eGFR of $\leq 60 \mathrm{~mL} / \mathrm{min} / 1.73 \mathrm{~m}^{2}$. The AKI was defined according to KDIGO criteria as an increase in the serum creatinine levels of $\geq 0.3 \mathrm{mg} / \mathrm{dL}$ within 48 hours or an increase of 1.5 times above baseline known or presumed to have occurred within the previous 7 days. Our primary objective was to determine occurrence of AKI in both the categories and to determine the percentage of patients who have progressed to RRT following OPCABG.

Despite the success of CABG with $\mathrm{CPB}$, the deleterious effects of $C P B$ have been well documented. ${ }^{9-11}$ The recent success of OPCABG offered an opportunity to avoid CPB and its side-effects. OPCABG demonstrated an overall early benefit, especially in patients traditionally considered at high risk for CABG. Recent studies confirmed that coronary grafting on the beating heart is a viable alternative to conventional on-pump CABG and provides good long-term graft patency. ${ }^{12-14}$ Acute renal failure necessitating the use of RRT is a rare but serious complication after CPB. However, AKI needing RRT is associated with an in-hospital mortality of 50 to $70 \%{ }^{15-17}$

A factor that likely affects risk of AKI in OPCABG is intrinsic genetic variability. Identification of genetic factors may influence the therapeutic strategy in dealing with the patients at high risk of developing AKI. Previously, it was reported that polymorphism of ACE I/D and APO-E genes is associated with development of AKI in cardiac surgery. ${ }^{18,19}$

Various studies have looked into patient factors associated with the development of AKI following cardiac surgery. In a multivariate model, the preoperative patient characteristics most strongly associated with postoperative severe renal insufficiency included advanced age, female sex, white blood cell count $>12,000 / \mathrm{mm}^{3}$, previous CABG, history of ongoing congestive heart failure, peripheral vascular disease, hypertension, diabetes, and preoperative IABP. ${ }^{20}$

Despite concern for almost half a century over the gravity of renal dysfunction as a complication, AKI persists as a prevalent and major predictor of early mortality after cardiac surgery. ${ }^{3}$ Although some of the damage associated with AKI simply reflects its association with other serious complications (e.g., sepsis) as an "epiphenomenon," there is also compelling evidence that AKI itself contributes to unfavorable outcome. ${ }^{21,22}$ Accumulation of uremic toxins other than urea and creatinine has widespread adverse effects on most organ systems. ${ }^{23}$ Although mostly studied in CKD, inadequate clearance of uremic toxins adversely affects survival. ${ }^{24}$ Even when postoperative dialysis is avoided, the powerful relationship of AKI with adverse outcome continues to stimulate the search for treatment options to protect the kidney. Postoperative renal dysfunction is a known complication following cardiac surgeries, the cause for which is multifactorial, but primarily attributed to factors relating to renal hypoperfusion, occurring due to insult to the kidney before, during, or after CPB.

Tabata et $\mathrm{al}^{25}$ conducted a study to know the role of renal function in outcomes of CABG. According to this study, renal dysfunction of the patient, whether it is severe or mild, is a main prediction measure of raised morbidity and mortality after CABG. Many studies showed the efficacy of OPCABG technique in reducing morbidity and mortality in patients with renal function. This study concluded that off-pump complete revascularization in patients with renal dysfunction provides less operative morbidity and mortality. Renal dysfunction is not a predictor of short survival of OPCABG, although it could predispose patients to longer ICU and in-hospital stay. ${ }^{25}$ Our study demonstrated increased incidence of AKI in category B though this did not reach statistical significance; this may be explained as happening because (i) no patient in category B suffered from severe renal dysfunction preoperatively, (ii) scrupulous attention was paid to hydration and volume status, (iii) mean arterial pressure was maintained meticulously during the perioperative period, (iv) off-pump technique was used, which maintains pulsatile flow, and (v) nephrotoxic drugs were avoided.

According to Safaie et al, renal dysfunction predisposes patients to adverse outcomes after CABG. This study also stated that, for chronic renal disease patients not on dialysis with serum creatinine value of $2.5 \mathrm{mg} / \mathrm{dL}$ or more, there is a strong probability of postsurgery dialysis. ${ }^{26}$

\section{Limitations}

- This study included patients with mild and moderate CKD. There were no patients who had severe CKD with GFR value $\leq 30 \mathrm{~mL} / \mathrm{min} / \mathrm{m}^{2}$ body surface area.

- This is a retrospective, single-center study.

\section{Conflict of Interest}

None. 


\section{References}

1 Roth GA, Abate D, Abate KH, et al; GBD 2017 Causes of Death Collaborators. Global, regional, and national age-sex-specific mortality for 282 causes of death in 195 countries and territories, 1980-2017: a systematic analysis for the Global Burden of Disease Study 2017. Lancet 2018;392(10159) :1736-1788

2 Kyu HH, Abate D, Abate KH, et al; GBD 2017 DALYs and HALE Collaborators. Global, regional, and national disability-adjusted life-years (DALYs) for 359 diseases and injuries and healthy life expectancy (HALE) for 195 countries and territories, 19902017: a systematic analysis for the Global Burden of Disease Study 2017. Lancet 2018;392(10159):1859-1922

3 Conlon PJ, Stafford-Smith M, White WD, et al. Acute renal failure following cardiac surgery. Nephrol Dial Transplant 1999;14(5):1158-1162

4 Esper SA, Subramaniam K, Tanaka KA, Pathophysiology of cardiopulmonary bypass: Current strategies for the prevention and treatment of anemia, coagulopathy, and organ dysfunction. Vol. 18, Seminars in Cardiothoracic and Vascular Anesthesia. Pittsburg, PA: SAGE Publications Inc; 2014 161-176

5 Elahi MM, Khan JS, Matata BM. Deleterious effects of cardiopulmonary bypass in coronary artery surgery and scientific interpretation of off-pump's logic. Acute Card Care 2006;8(4):196-209

6 Haase M, Bellomo R, Story D, et al. Effect of mean arterial pressure, haemoglobin and blood transfusion during cardiopulmonary bypass on post-operative acute kidney injury. Nephrol Dial Transplant 2012;27(1):153-160

7 Weir MR, Aronson S, Avery EG, Pollack CV Jr. Acute kidney injury following cardiac surgery: role of perioperative blood pressure control. Am J Nephrol 2011;33(5):438-452 http:// www.ncbi.nlm.nih.gov/pubmed/21508632 [Internet]

8 KimJW, Sim HT, Yoo JS, Kim DJ, Cho KR. Results of protocol-based perioperative management in off-pump coronary artery bypass grafting for patients with non-dialysis-dependent chronic kidney disease. Korean J Thorac Cardiovasc Surg 2016;49(6):427-434

9 Murphy GJ, Angelini GD. Side effects of cardiopulmonary bypass: what is the reality ? J Card Surg 2004;19(6):481-488

10 Paparella D, Yau TM, Young E. Cardiopulmonary bypass induced inflammation: pathophysiology and treatment. An update. Eur J Cardiothorac Surg 2002;21(2):232-244 http:// www.ncbi.nlm.nih.gov/pubmed/11825729 [Internet]

11 Omeroğlu SN, Kirali K, Güler M, et al. Midterm angiographic assessment of coronary artery bypass grafting without cardiopulmonary bypass. Ann Thorac Surg 2000;70(3):844-849, discussion 850 http://www.ncbi.nlm.nih.gov/pubmed/11016321 [Internet]

12 Mack MJ, Pfister A, Bachand D, et al. Comparison of coronary bypass surgery with and without cardiopulmonary bypass in patients with multivessel disease. J Thorac Cardiovasc Surg 2004;127(1):167-173
13 Yadava OP, Kundu A. "On" or "Off" pump coronary artery bypass grafting -is the last word out? Indian HeartJ2013;65(2):187-190

14 Lassnigg A, Schmidlin D, Mouhieddine M, et al. Minimal changes of serum creatinine predict prognosis in patients after cardiothoracic surgery: a prospective cohort study. J Am Soc Nephrol 2004;15(6):1597-1605 http://www.ncbi.nlm.nih. gov/pubmed/15153571 [Internet]

15 Rosner MH, Okusa MD. Acute kidney injury associated with cardiac surgery. Clin J Am Soc Nephrol 2006;1(1):19-32 http:// www.ncbi.nlm.nih.gov/entrez/query.fcgi?cmd=Retrieve\&d$\mathrm{b}=\&$ dopt=Citation\&list_uids=17699187 [Internet]

16 Skarupskienè I, Adukauskienè D, Kuzminskienė J, et al. Mortality prediction in patients with acute kidney injury requiring renal replacement therapy after cardiac surgery. Medicina (Kaunas) 2017;53(4):217-223

17 Lu JCT, Coca SG, Patel UD, Cantley L, Parikh CR; Translational Research Investigating Biomarkers and Endpoints for Acute Kidney Injury (TRIBE-AKI) Consortium. Searching for genes that matter in acute kidney injury: a systematic review. Clin J Am Soc Nephrol 2009;4(6):1020-1031

18 Isbir SC, Tekeli A, Ergen A, et al. Genetic polymorphisms contribute to acute kidney injury after coronary artery bypass grafting. Heart Surg Forum 2007;10(6):E439-E444 http:// www.ncbi.nlm.nih.gov/pubmed/17921131 [Internet]

19 Alge JL, Arthur JM. Biomarkers of AKI: a review of mechanistic relevance and potential therapeutic implications. Clin J Am Soc Nephrol 2015;10(1):147-155

20 Brown JR, Cochran RP, Leavitt BJ, et al; Northern New England Cardiovascular Disease Study Group. Multivariable prediction of renal insufficiency developing after cardiac surgery. Circulation 2007;116(11, Suppl):I139-I143

21 Meldrum KK, Meldrum DR, Meng X, Ao L, Harken AH. TNF- $\alpha$-dependent bilateral renal injury is induced by unilateral renal ischemia-reperfusion. Am J Physiol Heart Circ Physiol 2002;282(2):H540-H546

22 Serteser M, Koken T, Kahraman A, Yilmaz K, Akbulut G, Dilek ON. Changes in hepatic TNF- $\alpha$ levels, antioxidant status, and oxidation products after renal ischemia/reperfusion injury in mice. J Surg Res 2002;107(2):234-240

23 Cohen G, Hörl WH. Retinol binding protein isolated from acute renal failure patients inhibits polymorphonuclear leucocyte functions. Eur J Clin Invest 2004;34(11):774-781

24 Vanholder R, De Smet R, Glorieux G, Dhondt A. Survival of hemodialysis patients and uremic toxin removal. In: Artificial Organs. 2003 218- 223

25 Tabata M, Takanashi S, Fukui T, et al. Off-pump coronary artery bypass grafting in patients with renal dysfunction. Ann Thorac Surg 2004;78(6):2044-2049

26 Safaie N, Chaichi P, Habibzadeh A, Nasiri B. Postoperative outcomes in patients with chronic renal failure undergoing coronary artery bypass grafting in Madani Heart Center: 2000-2010. J Cardiovasc Thorac Res 2011;3(2):53-56 